\title{
Assessment of alcoholic beverage addiction in Nigerian secondary school adolescents: a cross-sectional study using a self-administered questionnaire adapted from a validated WHO substance use questionnaire
}

\author{
CLIFFORD ONUORAH OKIKE ${ }^{1, A, B, E, F}$, UZOAMAKA VIVIAN MUONEKE ${ }^{2, \text { B-F, }}$
} ORCID ID: 0000-0003-2607-1002

\author{
PIUS CHUKWUKA MANYIKE ${ }^{3, F, G}$, BENSON NNAMDI ONYIRE ${ }^{3, F, G}$, OBINNA AJAEGBU ${ }^{1, B, F}$, \\ SAMUEL NKACHUKWU UWAEZUOKE', E, F
}

\author{
${ }^{1}$ Department of Paediatrics Federal Medical Centre, Asaba, Delta, Nigeria \\ ${ }^{2}$ Department of Paediatrics, College of Medicine, University of Nigeria Teaching Hospital, Ituku-Ozalla, Enugu, Nigeria \\ ${ }^{3}$ Department of Paediatrics, College of Medicine, Ebonyi State University, Federal Teaching Hospital, Abakaliki, \\ Ebonyi State, Nigeria
}

A - Study Design, B - Data Collection, C - Statistical Analysis, D - Data Interpretation, E - Manuscript Preparation, F - Literature Search, G - Funds Collection

\begin{abstract}
Summary Background. Alcoholic beverage addiction among adolescents appears to be a global problem. However, its prevalence among secondary school adolescents in south-east Nigeria is poorly documented.

Objectives. To determine the prevalence of alcoholic beverage addiction among secondary school adolescents in a south-eastern Nigerian city.

Material and methods. 500 adolescents aged 12-19 years were recruited from 5 out of 9 secondary schools in a south-eastern Nigerian city by random sampling. The validated World Health Organization (WHO) drug-use questionnaire was adapted for the study and administered to these students. Data was analysed using descriptive and inferential statistics on SPSS Version 16.0. The level of statistical significance was set at $p<0.05$.

Results. The prevalence of alcoholic beverage addiction was $48.2 \%$ (236/490) with a male: female ratio of 2.4:1. The addiction rate was highest amongst students aged $18-19$ years $(55.4 \%, 93 / 168, p=0.001)$ and students from the middle socio-economic class $(28 / 45$, $62.2 \%, p=0.001$ ). Approximately $49 \%$ of the addicted students were initiated into consumption of alcoholic beverages by their peers, while $56.8 \%$ used it in order to achieve euphoria.

Conclusions. The prevalence of alcoholic beverage addiction among secondary school adolescents in this study is seen as high. Factors such as male gender, peer-group pressures, middle socio-economic class and being older were significant contributors to this high rate of alcohol addiction. Parental divorce and parental deaths were equally contributory to this high rate.

Key words: addiction medicine, alcoholic beverages, adolescent, peer influence, Nigeria.
\end{abstract}

Okike CO, Muoneke UV, Manyike PC, Onyire BN, Ajaegbu O, Uwaezuoke SN. Assessment of alcoholic beverage addiction in Nigerian secondary school adolescents: a cross-sectional study using a self-administered questionnaire adapted from a validated WHO substance use questionnaire. Fam Med Prim Care Rev 2020; 22(1): 49-53, doi: https://doi.org/10.5114/fmpcr.2020.92505.

\section{Background}

Alcohol is a psychoactive substance which exerts a major effects on the brain and psychological functioning, resulting in such effects as sedation and a change in mood or behaviour, and it also possesses habit-forming potentials [1, 2]. Addiction is defined as uncontrollable or excessive substance craving or use that persists even in the face of negative consequences [3, 4].

In Nigeria, the use of alcoholic beverages during ceremonies to facilitate social interactions dates back to ancient times [5, 6]. Studies in Nigeria [5, 7-10], Ethiopia [11], the United States $[12,13]$ and by the World Health Organization (WHO) $[14]$ show that alcohol is the major form of substance abuse among adolescents. For instance, an addiction rate of $9.5 \%$ was reported in a south-eastern Nigerian city [6], while a similar rate of 9.3\% was documented amongst female secondary school students in a south-western Nigerian city [7]. Elsewhere in the northern-central part of the country, an addiction rate of $21 \%$ was noted
[15], while in a city in south Nigeria, a rate as high as $55 \%$ was reported [16]. Furthermore, other authors in north-western $\mathrm{Ni}$ geria showed that $36.2 \%$ of a cohort of secondary school students was addicted to alcoholic beverages [17]. In a more recent nationwide study in Nigeria, the prevalence of harmful use of alcohol was $34.7 \%$ [18], while earlier in 2016, the WHO reported a rate of heavy episodic drinking in Nigeria totalling $45.4 \%$ [19].

The relationship between religious adherence and alcohol addiction has been considered by researchers [11, 20-26]. Most of these studies showed that alcohol use was inversely related to frequency of participation in religious activities. While some reported more use and abuse among Muslims [26, 27], others demonstrated more use and abuse among Christians [20, 23]. On the other hand, others reported more use among African traditional worshippers [25].

Several reasons have been given for this addiction among adolescents. These include the urge to emulate peers and the desire to use advertising artists of alcoholic brands as role models [28-33]. 
Although attempts have been made to document the prevalence rates of alcoholic beverage addiction in Nigerian adolescents, a small number of such studies exist in south-eastern $\mathrm{Ni}$ geria. The present study aims to determine the prevalence rate of this addiction and the contributory factors among secondary school adolescents in a south-eastern Nigerian city.

\section{Objectives}

It is a known fact that in adults, addiction to alcohol is associated with several negative consequences, such as violence, stealing and other anti-social activities among those who indulge in this practice. The objective of this research was to determine the prevalence of alcoholic beverage addiction among secondary school adolescents in an attempt to highlight the fact that addiction to alcohol also occurs among secondary school adolescents in the study area. We also tried to identify predisposing factors to alcohol addiction among these adolescents.

This research is important to family medicine practice, because they may actually be the first group to give care to these addicted adolescents who may present with uncommon symptoms. When armed with the knowledge of this prevalence, diagnosis and possible referral to appropriate specialists for proper management become more tenable.

\section{Material and methods}

\section{Study design}

The study was a cross-sectional survey.

\section{Study setting}

This study was carried out among adolescents in senior secondary II and III (SSII and SSIII) schools in the Abakaliki municipality, Ebonyi State, in south-eastern Nigeria from January to March 2008.

\section{Study participants}

There are nine secondary schools in the Abakaliki Metropolis, out of which five schools comprising two public co-educational schools, one private co-educational school, one male and one female public school were selected by simple balloting.

For every school visited, all the students in SSII and III were stratified into male and female student groups, and 50 respondents were selected from each stratum using a systematic random sampling technique. A total of 500 respondents ( 100 from each school) were used for this study.

Interviews using structured questionnaires adapted from the WHO [24] student drug-use questionnaire (already tested and validated in the Nigerian student population) [25] were distributed to the respondents for completion. The questionnaire was prepared in English, was self-administered and was administered after explaining the purpose of the study. The majority of the responses were: "Yes", "No" and "Not Sure" Other responses were "Agree", "Strongly Agree", "Disagree" , "Strongly Disagree" and "Not Sure".

\section{Variables}

The questions focused on various sub-themes, like socio-demographic information, source of initiation to alcohol use, reasons for alcohol use and the number of bottles drank per day. Students who drank four bottles or more per day were classified as heavy drinkers, while those dinking less were classified as non-heavy drinkers.

Socio-economic classes of the respondents were determined using their mother's educational attainment and father's occupation [34].

\section{Data sources/measurement}

The data collected was manually sorted out, edited and coded. Ten completed questionnaires were rejected on the ground of inconsistencies.

\section{Sample size determination}

The total population of students in SSII and SSIII in the eleven urban schools, as documented by Ebonyi State Secondary Education Board in March 2007, was 5,784 [35]. Based on this figure, the minimum sample size of 349 was calculated using the formula: $n=Z^{2} P q / \mathrm{d}^{2}[36]$.

However, to increase sensitivity and to make allowance for returned questionnaires, this sample size was increased to 500 .

\section{Statistical methods}

Data from the remaining 490 questionnaires was entered into a computer and analysed using the Statistical Package for Social Sciences (SPSS) Version 15.0 (SPSS Inc., Chicago, Illinois, USA). Frequency tables were generated for the demographic characteristics of the respondents. Qualitative variables were summarised by proportions. The chi-square test was used to determine levels of significance. Levels $p<0.05$ were considered statistically significant.

\section{Ethics approval and consent to participate}

Ethical approval was sought and obtained from the Ethics Committee of Ebonyi State Secondary Education Board Abakaliki on 23 November 2007 with the protocol number: EBSSEB/ /AISCH/013. The principals were informed, while consent was obtained from the parents of the younger students and older students of the selected schools.

Consent to publish the obtained data was also obtained from both the parents and respondents, respectively.

\section{Results}

\section{Participants}

The sample $(n=490)$ comprised 246 males $(50.2 \%)$ and 244 females $(49.8 \%)$ with a male: female ratio of 1.01:1.0.

\section{Descriptive data}

490 of the participants returned completed questionnaires.

The age range of the participants was $12-19$ years, with a mean age of $16.1(0.8)$ years in all the schools. Approx. $50.2 \%$ of the students were in SSIII, while $49.8 \%$ were in SSII.

\section{Main results}

Approx. $67.5 \%(166 / 246)$ of the male students were addicted to alcoholic beverages, while only $28.7 \%(70 / 244)$ of their female counterparts were addicted. This difference in the addiction rate between the male and female respondents was statistically significant $(p<0.001)$. The overall prevalence rate of alcoholic beverage addiction was $48.2 \%$, with a male: female ratio of 2.4:1 (Table 1).

\begin{tabular}{|l|l|l|l|}
\hline \multicolumn{4}{|l|}{ Table 1. Alcohol beverage addiction by gender } \\
\cline { 1 - 3 } Gender & Addicted & Non-addicted & $p$ \\
\hline Male (\%) & $166(70.3)$ & $80(31.5)$ & $p<0.0001$ \\
\cline { 1 - 3 } Female (\%) & $70(29.7)$ & $174(68.5)$ & \\
\cline { 1 - 3 } Total & $\mathbf{2 3 6 ( 1 0 0 )}$ & $\mathbf{2 5 4 ( 1 0 0 )}$ & \\
\cline { 1 - 2 }
\end{tabular}

Alcoholic beverage addiction was found to be the most common among adolescents aged $18-19$ years (55.4\%; 93/168) 


\begin{tabular}{|c|c|c|c|c|c|}
\hline Age (years) & $\begin{array}{l}\text { No. of students in } \\
\text { each age group }\end{array}$ & $\begin{array}{l}\text { Students not addicted to alcohol } \\
n(\%)\end{array}$ & $\begin{array}{l}\text { Students addicted to alcohol } \\
n(\%)\end{array}$ & Total (\%) & $p$ \\
\hline $12-13$ & 1 & $0(0)$ & $1(100 \%)$ & $1(100)$ & \multirow[t]{4}{*}{$p<0.001$} \\
\hline $14-15$ & 125 & $87(69.6)$ & $38(30.4)$ & $125(100)$ & \\
\hline $16-17$ & 196 & $92(46.9)$ & $104(53.1)$ & $196(100)$ & \\
\hline $18-19$ & 168 & $75(44.6)$ & $93(55.4)$ & $168(100)$ & \\
\hline
\end{tabular}

\begin{tabular}{|c|c|c|c|c|}
\hline Socio-economic status ( $n$ ) & $\begin{array}{l}\text { No. of students in each SES } \\
\text { group }\end{array}$ & $\begin{array}{l}\text { No. of students addicted to } \\
\text { alcohol }(n)\end{array}$ & Percentage (\%) & $p$ \\
\hline Upper & 276 & 126 & 45.7 & \multirow[t]{4}{*}{$p<0.001$} \\
\hline Middle & 45 & 28 & 62.2 & \\
\hline Lower & 119 & 39 & 32.8 & \\
\hline Total & 440 & 193 & & \\
\hline Family background & $\begin{array}{l}\text { No. of students } \\
(n)\end{array}$ & $\begin{array}{l}\text { No. of students addicted to } \\
\text { alcohol }(n)\end{array}$ & Percentage (\%) & $p$ \\
\hline Parents still married & 345 & 137 & 39.7 & \multirow[t]{4}{*}{$p<0.001$} \\
\hline Parents divorced & 28 & 28 & 100 & \\
\hline Parents dead & 117 & 71 & 60.7 & \\
\hline Total & 490 & 236 & 48.2 & \\
\hline
\end{tabular}

Note: The socio-economic class of 50 students were not determined, because they did not indicate their mothers' educational attainment or their fathers' occupation.

when compared to those aged $14-15$ years and $16-17$ years, with addiction rates of $30.4 \%(38 / 125)$ and $53.1 \%(104 / 196)$, respectively, as shown in Table 2 . The difference in the addiction rates of various age ranges reached a significant level $(p<0.001)$.

Alcoholic beverage addiction was most common among adolescents from middle socio-economic classes (62.2\%, 28/45, $p$ $<0.001$ ) compared to adolescents from upper and lower socio-economic classes, with addiction rates of $45.7 \%(126 / 276)$ and $32.8 \%(39 / 119)$, respectively.

$100 \%(28 / 28)$ of the students whose parents were divorced drank alcoholic beverages to a level compatible with addiction, while $60.7 \%(71 / 117)$ and $39.7 \%(137 / 345)$ of students whose parents were dead and whose parents were still married/living together, respectively, were addicted to alcoholic beverages, as shown in Table 3.

Most students who were addicted to alcoholic beverages $(48.7 \%, 115 / 236)$ were initiated into using it by their friends. Those who started using it through parental influence amounted to $33.9 \%(80 / 236)$, while $15.3 \%(36 / 236)$ and $2.1 \%(5 / 236)$ were initiated through advertisement and classroom lecture on alcohol.

\begin{tabular}{|l|}
\hline Table 4. Initiation and reasons for alcohol use \\
\hline Source of initiation frequency percentage \\
\hline Friends 115 (48.7) \\
Father 69 (29.2) \\
Mother $11(4.7)$ \\
Advert 36 (15.3) \\
Classroom lecture on alcohol 5 (2.1) \\
Total 236 (100) \\
\hline Reasons for alcohol use \\
\hline The taste is pleasant $19(8.0)$ \\
To feel euphoria $134(56.8)$ \\
To talk to people 36 (15.3) \\
To forget worries 37 (15.7) \\
Curiosity 10 (4.2) \\
Total 236 (100) \\
\hline
\end{tabular}

Approximately 48\% (134/236) drank alcoholic beverages because they wanted to experience euphoria, 15.3\% (36/236) drank it to be able to communicate with the opposite sex, while $15.7 \%(37 / 236)$ drank alcoholic beverages to forget worries. $8 \%$ $(19 / 236)$ and $4.2 \%(10 / 236)$ drank alcohol because they liked the taste and due to curiosity, respectively (Table 4).

\section{Discussion}

\section{Key results/interpretation}

The prevalence rate of alcoholic beverage addiction in this study is $48.2 \%$, which is higher than the rates of $9.5 \%, 21 \%$, $34.7 \%$ and $36.2 \%$ documented in later studies done between 2015 and 2019 [7, 15, 17, 18]. This finding may suggest that alcoholic beverage addiction is on the decline. However, our prevalence rate appears to be lower than the $55 \%$ reported in Abraka, Delta State, by Adje et al. in 2015 [16]. However, our prevalence rate appears to be lower than 55\% reported in Abraka, Delta state by Adje et al. in 2015 [16]. Most riverine areas in Nigeria (towns located along a body of water e.g. river) as part of their culture are associated with excess alcohol consumption, hence, Abraka which is one of the riverine towns in Delta State, Nigeria is equally associated with high alcohol consumption [16]. The higher prevalence rate of $48.2 \%$ in this current study may also be due to the wide availability and unrestricted sale of alcohol in the municipality where the study was conducted.

This study has also shown that male adolescents were more addicted to alcoholic beverage than their female counterparts, which corroborates with studies in Ibadan [20], llorin and Nasarawa [22]. This finding is not surprising, because alcoholic beverage consumption by females is culturally unacceptable in Ibadan, in the South West and Ilorin/Nasarawa, in the north-central part of the country and, most importantly, in the environment of the current study $[6,8,9]$.

Students from middle socio-economic classes were most significantly addicted to alcoholic beverages when compared to respondents in other social classes. This observation is in contrast with the other reports [31-33], which show that adolescents from the upper socio-economic class were addicted more than adolescents from other social classes. This may mean that 
parents in these middle socio-economic classes show more a permissive attitude to the use of alcoholic beverages by their children than parents in the other social strata. It may also suggest that these items of addiction may actually be more accessible and available to these adolescents.

Alcoholic beverage addiction occurred most commonly among students whose parents were divorced or among those whose parents were dead. This finding agrees with that of previous reports which show that students from such homes have a high prevalence rate of alcohol addiction $[8,25,27,30]$. This is not surprising, because the absence of parental supervision of adolescents from these homes may have strengthened an attachment to peers in school with similar addiction.

A majority of the students who were addicted to alcoholic beverages were initiated into its use by their friends. This finding agrees with the reports of many authors [28, 30-32] and confirms the explanation by one author that in search for independence from parental control, adolescents turn towards people of similar age or interests, such as peer groups [30]. The search for this independence may paradoxically lead to a dependence on peer group and the demands of the group, such as alcohol use.

The study revealed the fact that a significant number (29.2\%) of these students were initiated into the habit by their fathers. This is not surprising, since alcohol consumption is a well-known part of the Nigerian culture, especially in Igboland, where the study was conducted. It frequently forms a significant part of festivals and celebrations. Traditionally, in most towns in Igboland, men are known to prefer to attend such cultural festivals with their sons, and they inadvertently end up introducing them to consumption of alcohol.

Approx. $15.3 \%$ of the respondents who were addicted to alcoholic beverages were initiated into it through advertisement. This finding lends credence to the report by Norman [28] and
Saffer [32] that alcohol advertising increases its use and subsequent abuse. The reason why advertisement is a significant factor in alcohol addiction is that since music or sports stars are used in the advertisement of alcoholic beverages, younger individuals have the impression that their consumption is desirable, acceptable and could make them be more like these models.

\section{Limitations to the study}

The study was conducted nearly 10 years ago, but was not published at the time of the study.

The questionnaire used for the study was adapted from the WHO substance use questionnaire, since this was the only questionnaire available and accessible to us as at the time of the study.

\section{Conclusions}

Alcoholic beverage addiction among secondary school adolescents in the present study is high and more common in males than females. Alcoholic beverage addiction among secondary school adolescents in the present study is high and commoner in males than females. Poor parenting, peer influence, and alcoholic beverage advertisements were the key factors that contributed to addiction.

It is the belief of the authors that if this high prevalence rate is not curbed appropriately and timely, unwanted and criminal consequences could result. Re-introducing guidance and counselling as a subject in the academic curriculum of all secondary schools may provide a valuable solution.

Acknowledgement. We wish to acknowledge the parents of the students in the study, as well as the students and school management for giving us the opportunity to carry out this research on their children and students, respectively.

Source of funding: This work was funded from the authors' own resources.

Conflicts of interest: The authors declare no conflicts of interest.

\section{References}

1. World Health Organization. Management of substance abuse [cited 27.08.2019]. Available from URL: https://www.who.int/substance _ abuse/terminology/psychoactive_substances/en/.

2. Vocabulary.com. Psychoactive substance; dictionary definition [cited 27.08.2019]. Available from URL: https://www.vocabulary.com/ dictionary/psychoactive\%20substance.

3. Wise R, Koob G. The development and maintenance of drug addiction. Neuropsychopharmacol 2014; 39: 254-262, doi: 10.1038/ npp.2013.261.

4. National Institute on Drug Abuse. The science of drug use and addiction: the basics [cited 27.08.2019]. Available from URL: https:// www.drugabuse.gov/publications/media-guide/science-drug-use-addiction-basics.

5. Adekeye OA, Adeusi SO, Chenube OO, et al. Assessment of alcohol and substance use among undergraduates in selected private universities in Southwest Nigeria. IOSR-JHSS 2015; 20(3): 1-7, doi: 10.9790/0837-20320107.

6. Egbuonu I, Ezechukwu CC, Chukwuka JO, et al. Substance abuse among female secondary school students in Anambra State, South Eastern Nigeria. Nig J Clin Pract 2004; 7: 53-55.

7. Awosusi AO, Adegboyega JA. Alcohol consumption and tobacco use among secondary school students in Ekiti State, Nigeria. International Journal of Education and Research 2015; 3(5): 11-20.

8. Anochie IC, Nkanginieme KEO. Social correlates of drug use among secondary school students in Port Harcourt, Southern Nigeria. Sahel Med J 2000; 3: 87-92.

9. Okwaraji FE. Substance abuse among secondary school adolescents in Enugu. J Coll Med 2006; 11(2): 130-135.

10. Effiom DD, Ejue JB, Effiong UU. Prevalence and types of drugs and substance abuse as expressed by youths in Calabar Nigeria. Nigerian $J$ Guidance and Counselling 2005; 10(1): 134-141.

11. Birhanu AM, Bisetegn TA, Woldeyohannes SM. High prevalence of substance use and associated factors among high school adolescents in Woreta Town, Northwest Ethiopia: multi-domain factor analysis. BMC Public Health 2014; 14(1): 1186, doi: 10.1186/1471-2458-141186.

12. Swendsen J, Burstein M, Case B, et al. Use and abuse of alcohol and illicit drugs in US adolescents: results of the national comorbidity survey-adolescent supplement. Arch Gen Psychiatry 2012; 69(4): 390-398.

13. Substance Abuse and Mental Health Services Administration. (2017). Key substance use and mental health indicators in the United States: Results from the 2016 National Survey on Drug Use and Health (HHS Publication No. SMA 17-5044, NSDUH Series H-52). Rockville (MD): Center for Behavioral Health Statistics and Quality, Substance Abuse and Mental Health Services Administration. Available from URL: https://www.samhsa.gov/data/.

14. WHO. Global status report on alcohol. Geneva: World Health Organization; 1999. 
15. Eniojukan, JF, Chichi RM. Substance abuse among adolescents: prevalence and patterns of alcohol use in benue state, Nigeria. Journal of Pharmacy 2015; 12(4): 2250-3013.

16. Adje DEU, Oyita GI, Eniojukan JF. Substance abuse among adolescents: prevalence and patterns of alcohol consumption among senior secondary school students in Abraka, Delta State, Nigeria. Sch Acad J Pharm 2015; 4(1): 63-69.

17. Bassi AP, Idoko L, Ogundeko TO, et al. Substance abuse and its prevalence among secondary school adolescents in Kagoro, Kaduna State, Nigeria. WJRR 2017; 5(1): 11-16.

18. Harhay MO, Alemu W, Adewole IF. Epidemiology of harmful use of alcohol in Nigeria: a systematic review and meta-analysis. Am J Drug Alcohol Ab 2019; 45(5): 438-450.

19. World Health Organization. Alcohol consumption levels and patterns in Nigeria in 2016 [cited 27.08.2019]. Available from URL: https:// www.who.int/substanceabuse/publications/global_alcohol_report/pr.

20. Lasebikan VO, Ola BA. Prevalence and correlates of alcohol use among a sample of Nigerian Semirural Community Dwellers in Nigeria. Journal of Addiction 2016; 2831594: 6, doi: 10.1155/2016/2831594.

21. Koenig LB, Haber JR, Jacob T. Childhood religious affiliation and alcohol use and abuse across the lifespan in alcohol-dependent men. Psychol Addict Behav 2011; 25(3): 381-389.

22. Ajayi Al, Owolabi EO, Olajire OO. Alcohol use among Nigerian university students: prevalence, correlates and frequency of use. $B M C$ Public Health 2019; 19(1): 752.

23. Okolie KC, Obinwanne SC. Substance use among students of tertiary institutions in Anambra State, Nigeria. Medzik Journal 2002; 4: 25-30.

24. Baena B, Falcón C, Caperos J, et al. The role of religion and religiosity in alcohol consumption in adolescents in Spain. Journal of Religion and Health 2018, doi: 10.1007/s10943-018-0694-z.

25. Brisibe S, Ordinioha B. Socio-demographic characteristics of alcohol abusers in a rural ljaw community in Bayelsa State, South-South Nigeria. Ann Afr Med 2011; 10: 97-102.

26. Oshodin GO. Alcohol abuse: a case study of secondary school students in a rural area of Benin district, Nigeria. Drug Alc Depend 1981; 8: 207-223.

27. Bada FO, Adebiyi DR. Alcohol consumption behaviour among Secondary School students in Nigeria. Journal of Educational and Social Research 2014; 4(3): 507-510.

28. Norman I. Prevalence of alcohol consumption and factors influencing alcohol use among the youth of Tokorni-Hohoe, Volta Region, Ghana. Science Journal of Public Health 2017; 5: 205-214.

29. Grenard JL, Dent CW, Stacy AW. Exposure to alcohol advertisements and teenage alcohol-related problems. Pediatrics 2013; 131(2): 369-379.

30. Ghuman S, Meyer-Weitz A, Knight S. Prevalence patterns and predictors of alcohol use and abuse among secondary school students in southern KwaZulu-Natal, South Africa: demographic factors and the influence of parents and peers. S Afr Fam Pract 2014; 54: $132-138$.

31. Fletcher JM. Peer influences on adolescent alcohol consumption: evidence using an instrumental variables/fixed effect approach. J Popul Econ 2012; 25: 1265, doi: 10.1007/s00148-011-0365-9.

32. Saffer H. Alcohol advertising and youths. J Stud Alc Drugs 2002: 14: 173-181.

33. Chen M, Grube JW, Bersamin M, et al. Alcohol advertising: what makes it attractive to youths? J Health Commun 2005: 10: 553-565.

34. Okpere $\mathrm{E}$, Olusanya $\mathrm{O}$. The importance of social class in voluntary fertility control in a developing country. West Afri J Med 1985: 4: 205-212.

35. Statistics and Planning Unit. Available at Statistics unit, Post Primary Schools Education Board, Ministry of Education, Ebonyi State, South-East Nigeria. Accessed on August, 2007.

36. Lwang SK, Type CY. Teaching health statistics: twenty lessons and seminar outlines. Geneva: WHO; 1986: 67-74.

Tables: 4

Figures: 0

References: 36

Received: 18.06.2019

Reviewed: 14.07.2019

Accepted: 25.09.2019

Address for correspondence:

Uzoamaka Vivian Muoneke, MD

Department of Paediatrics

College of Medicine

University of Nigeria

University of Nigeria Teaching Hospital Enugu

Nigeria

Tel.: +234 8037432258

E-mail: uzoamakamuoneke@gmail.com 